REFERENCE:

[1] Viola S, Felici E, Magni-Manzoni S, et al. Development and validation of a clinical index for assessment of long-term damage in juvenile idiopathic arthritis. Arthritis Rheum 2005;52:2092-102.

Disclosure of Interest: None declared

DOI: 10.1136/annrheumdis-2018-eular.1248

\section{AB1106 DEPRESSION AND ANXIETY IN PAEDIATRICSYSTEMIC LUPUS ERYTHEMATOSUS. A SYSTEMATIC REVIEW}

M.C. Quilter ${ }^{1,2}$, D. Korczak ${ }^{1,2}{ }^{1}$ Department of Psychiatry, The Hospital For Sick Children; ${ }^{2}$ University of Toronto, Toronto, Canada

Background: Depression and anxiety are common and treatable childhood mental health disorders that have been reported to impact outcomes for individuals with childhood-onset Systemic Lupus Erythematosus (cSLE) ${ }^{1}$. Research into the prevalence of depression/anxiety and cSLE comorbidity has reported conflicting results, and to our knowledge, no previous review of these data has been undertaken.

Objectives: To synthesise current knowledge regarding the association of depression and anxiety disorders with CSLE among paediatric patients.

Methods: Studies were identified through a comprehensive search of MEDLINE, EMBASE, PsychINFO, LILACS and Web Of Science (from database inception July 2017) using MESH headings and Keywords for 'lupus erythematosus', and 'depression' or 'anxiety'. Included studies measured depression and/or anxiety symptoms prospectively among children and youth 8 to 21 years of age with a diagnosis CSLE. Data were extracted by two independent coders and where discrepancies occurred, agreement was reached by consensus.

Results: Sixty-two studies met criteria for full text review, and of these, 13 studies were included in the final analysis. The majority $(80 \%)$ of studies were of crosssectional design, with sample sizes ranging from 14 to 100 (mean=47) participants. The mean age of participants was 15.6 years and participants were predominantly female. Prevalence rates for depression ranged from $6.7 \%$ to $54 \%$. Anxiety symptom prevalence was $20 \%$ to $34 \%$. All studies employed self-report instruments to assess depression and anxiety; none of the studies utilised semistructured diagnostic interview to make psychiatric diagnoses. Significant heterogeneity precluded meta-analysis of the data.

Conclusions: Depression and anxiety may be common comorbidities of cSLE however current research is limited by a paucity of studies, small sample sizes and an inability to confirm psychiatric diagnoses. Future research addressing these limitations is needed.

\section{REFERENCE:}

[1] Kohut SA, Williams T, Jayanthikumar J, Landolt-Marticorena C, Lefebvre A, Silverman E, Levy D: Depressive symptoms are prevalent in childhoodonset systemic lupus erythematosus (CSLE). Lupus 2013, 22(7):712-720

Disclosure of Interest: None declared

DOI: 10.1136/annrheumdis-2018-eular.3523

\section{\begin{tabular}{|l|l}
\hline AB1107 & TRANSITION FROM PAEDIATRIC TO ADULT
\end{tabular} RHEUMATOLOGY SERVICES IN NEWCASTLE TRUST HOSPITALS}

M. Obayi ${ }^{1}$, M. Lee ${ }^{2}$, A. Krishnakumar ${ }^{2} .{ }^{1}$ Newcastle University; ${ }^{2}$ Newcastle-UponTyne Hospitals, Newcastle, UK

Background: Transitional care is defined as "the purposeful, planned movement of adolescents and young adults with chronic physical and medical conditions from child-centred to adult-oriented healthcare systems."

In 2016, EULAR produced recommendations on how this transition process should occur within rheumatology. ${ }^{2}$

Objectives: To audit the Newcastle-Upon-Tyne Hospitals rheumatology transitional care service against EULAR recommendations.

Methods: EULAR recommendations were adapted into a questionnaire, which was reviewed and edited by several Young Adults (YAs) with Juvenile Idiopathic Arthritis (JIA) attending clinics.

Patients attending specialist YAJIA clinics between November 2017 and January 2018 were asked to complete the questionnaire; responses were audited against EULAR recommendations.

Results: 28 YAs with JIA completed the audit questionnaire (10 males and 18 females, age range 16-25). Not all questions were answered by all YAs.

Of the 17 patients with 'childhood-onset disease' (onset sage 10) 12\% (2/17) had their transition started by age 14 ('essential' recommendation) and none by age 11 (the 'ideal' recommendation). Of the 11 patients with 'adolescent-onset disease' (onset >age 10) 18\% (2/11) had their transition started at the time of diagnosis (EULAR recommendation 2).

$63 \%(17 / 27)$ of patients had $\geq 1$ 'direct' contacts with adult and paediatric rheumatology via a joint appointment (EULAR recommendation 3 ).

$11 \%(3 / 28)$ of patients were aware of a documented individual transition plan (EULAR recommendation 4).

$40 \%(6 / 15)$ were able to list $\geq 3$ multidisciplinary team (MDT) members that had positively impacted their care. $54 \%(15 / 28)$ were able to provide the name of a transition coordinator (EULAR recommendation 6).

$81 \%(21 / 26)$ of respondents 'agreed or strongly agreed' that they had been signposted to information on their condition, $48 \%(12 / 25)$ to peer support groups, mentoring schemes and charities, and $25 \%(6 / 24)$ to information sources on careers and finance. $64 \%$ (of patients were consulted on how they would like their parent/ carer to be involved in their care during and after their transition (EULAR recommendation 7).

$82 \%(23 / 28)$ of respondents reported having copies of letters concerning thei care and transition (EULAR recommendation 8).

Conclusions: Newcastle-upon-Tyne hospitals transition services are in line EULAR recommendations in terms of MDT involvement in the transition process and addressing the medical needs of patients during transition, whilst signposting them to other agencies and ensuring they have copies of communication.

The audit also identified areas for improvement including: the need for a single named coordinator for all patients; ensuring discussions with patients about the transition process begin at an earlier age, and making sure patients are aware of and able to contribute to their documented and individulised transition plan.

\section{REFERENCES:}

[1] Blum RW, Garell D, Hodgman $\mathrm{CH}$, et al. Transition from child-centered to adult healthcare systems for adolescents with chronic conditions. A position paper of the Society for Adolescent Medicine. J Adolesc Health 1993:14:570-6

[2] Foster HE, Minden $\mathrm{K}$, Clemente D, et al. EULAR/PReS standards and recommendations for the transitional care of young people with juvenile-onse rheumatic diseases Annals of the Rheumatic Diseases 2017;76:639-646

Disclosure of Interest: None declared

DOI: 10.1136/annrheumdis-2018-eular.6016

\section{AB1108 1 THE EFFICACY AND SAFETY OF TREATMENT OF 152 NON-SYSTEMIC JUVENILE IDIOPATHIC ARTHRITISPATIENTS WITH ETANERCEPT: FACTORS, ASSOCIATED WITH ACHIEVEMENT REMISSION AND RISK OF FLARE}

M. Kostik, I. Chikova, E. Isupova, M. Likhacheva, T. Likhacheva, M. Dubko, V. Masalova, L. Snegireva, E. Gaidar, O. Kalashnikova, V. Chasnyk. SaintPetersburg State Pediatric Medical University, Saint-Petersburg, Russian Federation

Background: Juvenile idiopathic arthritis (JIA) is the most frequent chronic inflammatory joint disease in childhood, required biologics administration if the previous therapy falls. Etanercept is the most worldwide biologic using in JIA patients.

Objectives: The aim of our study was to evaluate the efficacy and safety of etanercept in children with non-systemic categories of JIA and determine predictors of achievement of the remission and risk of flares.

Methods: In the retrospective observational study were included 152 children with non-systemic categories of JIA, treated with etanercept. Standard JIA measures and outcomes were utilised, remission was based on C. Wallace criteria (2004). We used descriptive statistics, $x^{2}$-test, Fisher's exact test, Mac-Nemar test, Mann-Whitny, Wilcoxon, Friedmann and log-rank tests, AUC-ROC analysis, odds ratio and relative risk calculation with Cox regression models.

Results: The cumulative remission was achieved in $58.8 \%$ patients during the trial. The maximum remission rates $(80 \%)$ were in children with treatment duration near the 5 years and increased from year to year. Patient who achieved remission had less JIA onset age $(p=0.015)$, age of inclusion in the study $(p=0.004)$ and age of etanercept administration $(\mathrm{p}=0.00007)$. The main predictors of achievement remission were $\mathrm{JIA}$ onset age $\leq 7.8$ years $(\mathrm{OR}=4,3(95 \% \mathrm{Cl}: 1.9-9.8), \mathrm{p}=0.0003)$, age of inclusion in the study $\leq 14.0$ years $(\mathrm{OR}=2.85(95 \% \mathrm{Cl}: 1.4-5.9), \mathrm{p}=0.00007)$ age of etanercept administration $\leq 10.0$ years (OR=3.5 $(95 \% \mathrm{Cl}: 1.7-7.2)$, $\mathrm{p}=0.0007)$, time before etanercept administration $\leq 2.4$ years $(\mathrm{OR}=2.7(95 \% \mathrm{Cl}$ : 1.3; 5.5), $\mathrm{p}=0.0007)$. In Cox regression model $(\mathrm{p}=0.007)$ HLA B27 positivity $(R R=2.15(95 \% \mathrm{Cl}: 0.98 ; 4.75), p=0.06)$ and time before etanercept administration $\leq 2.4$ years ( $R R=2.4(95 \% \mathrm{Cl}: 1.4 ; 4.4), \mathrm{p}=0.003)$ were main predictors of remission achievement. Polyarticular JIA increased the risk of flare compare to oligoarticular (RR=2.7 (95\%Cl: 0.9; 8.2), $p=0.08)$, then concomitant methotrexate decresed the risk of flare $(R R=0.32(0.1 ; 1.15), p=0.05)$ in Cox regression model. During the 